Cite this: RSC Adv., 2014, 4, 17549

\title{
Carbon aerogels from bacterial nanocellulose as anodes for lithium ion batteries
}

\author{
Liping Wang, ${ }^{a}$ Christina Schütz, ${ }^{\text {bc }}$ German Salazar-Alvarez ${ }^{\star b c}$ \\ and Maria-Magdalena Titirici ${ }^{\star d}$
}

Received 21st December 2013

Accepted 26th March 2014

Carbon aerogels with large open pores and high surface area are fabricated via pyrolysis of a readily available natural resource, e.g., bacterial nanocellulose (BNC) aerogels. Freeze-drying of the BNC hydrogels is used to preserve the 3D open network structure upon calcination whereas using Fe(III) improves the yield and $\mathrm{H}$ /

DOI: $10.1039 / c 3 r a 47853 j$

www.rsc.org/advances

$\mathrm{C}$ ratio. These carbon aerogels are explored as anodes in lithium ion batteries where it is shown that they deliver superior capacity retention and rate performance compared to other carbon-based materials.

\section{Introduction}

The search for alternative energy sources to fossil fuels has increased in the recent years due to growing environmental concerns and an increasing oil price. Conventional non-fossil energy sources (such as wind, solar, and hydroelectric power) deliver energy continuously whether it is used or not. As such, it is advantageous to develop energy storage media which can also be light and easy to transport. In this regard, lithium ion batteries (LIBs) are one of the best alternatives due to their relatively light weight, high energy and power density. ${ }^{1-4}$

Carbon is the most commonly used anode material in commercial LIBs because of its low price, low lithium ion intercalation potential and good cyclic stability. ${ }^{5}$ Nevertheless, since carbon anodes may suffer of poor rate performance due to a slow lithium diffusivity, ${ }^{5}$ intense efforts have been devoted to finding alternative anodes with different compositions, mostly oxides. ${ }^{6}$ However, the poor rate performance can be greatly improved by reducing the travel distance of the lithium ions within the carbon matrix. Mesoporous carbons have shown an improved rate performance and enhanced capacity, ${ }^{7,8}$ particularly in combination with carbon nanotubes. ${ }^{9}$ Carbon materials derived from renewable natural, abundant nanomaterials, e.g., cellulose, chitin, collagen, and silk, may play an important role as they are available at a very low cost and readily available in developing countries. ${ }^{10}$ Moreover, these renewable carbon

\footnotetext{
${ }^{a}$ Max Planck Institute of Colloids and Interfaces, Am Mühlenberg 1, 14476 Potsdam, Germany

${ }^{b}$ Department of Materials and Environmental Chemistry, Arrhenius Laboratory, Stockholm University, Stockholm,SE-106 91, Sweden.E-mail: german@mmk.su.se ${ }^{c}$ Wallenberg Wood Science Center, KTH, Teknikringen 56, Stockholm, SE-100 44, Sweden

${ }^{d}$ School of Materials Science and Engineering, Queen Mary University of London, Mile End Road, London, E1 4NS, UK. E-mail:m.m.titirici@qmul.ac.uk
}

materials can be produced using much simpler methodologies, i.e. pyrolysis $^{11,12}$ and hydrothermal carbonization. ${ }^{13,14}$

In this respect, nanocellulose ${ }^{15,16}$ is emerging as a cheap, abundant, biodegradable, and sustainable polymeric material with useful functional properties such as tailored hydro/oleophilicity, optical transparency, and remarkable mechanical performance both as films and aerogels. ${ }^{17-21}$ Particularly, bacterial nanocellulose (BNC), ${ }^{15,16}$ which is readily obtained from cell cultures of $G$. xylinum and widely available as a dessert in South-East Asia, ${ }^{22}$ has been suggested as a convenient scaffold for the preparation of functional materials with magnetic, ${ }^{23}$ optical, ${ }^{24}$ and mechanical properties due to their open network structure and low apparent density. ${ }^{16,22}$ While nanocellulose fibres have recently been used as substrates for the deposition of active battery components ${ }^{25,26}$ and also as binder and electrode separators, ${ }^{27}$ very little work has been focusing on the fabrication of electrically conducting nanocellulose-based systems where the open network structure is exploited..$^{28-30}$

In this work, we study the behaviour of a carbon aerogel network obtained through the pyrolysis of BNC aerogels as anode material in LIBs. The pyrolyzed fibres show a disordered structure with an enhanced surface area, resulting in anode materials with a good rate performance and capacity retention. Our results suggest that ordered graphitic layers are not a requirement for achieving high capacity, thus avoiding the use of high temperatures during the fabrication process.

\section{Results and discussion}

Fig. 1 shows freeze-dried BNC (FD-BNC, Fig. 1a-c) aerogel with a highly porous network and the preserved nanofibrillar network after pyrolysis at $900{ }^{\circ} \mathrm{C}$ (FD-BNC-900, Fig. 1d-f). The fiber thickness decreased from $c a .20-70 \mathrm{~nm}$ to about $20 \mathrm{~nm}$. The original monolith reduced considerably its volume after the pyrolysis mostly due to the loss of water and release of $\mathrm{CO}$ and $\mathrm{CO}_{2}$ occurred around $300^{\circ} \mathrm{C} .{ }^{31}$ Normally a direct calcination of a 

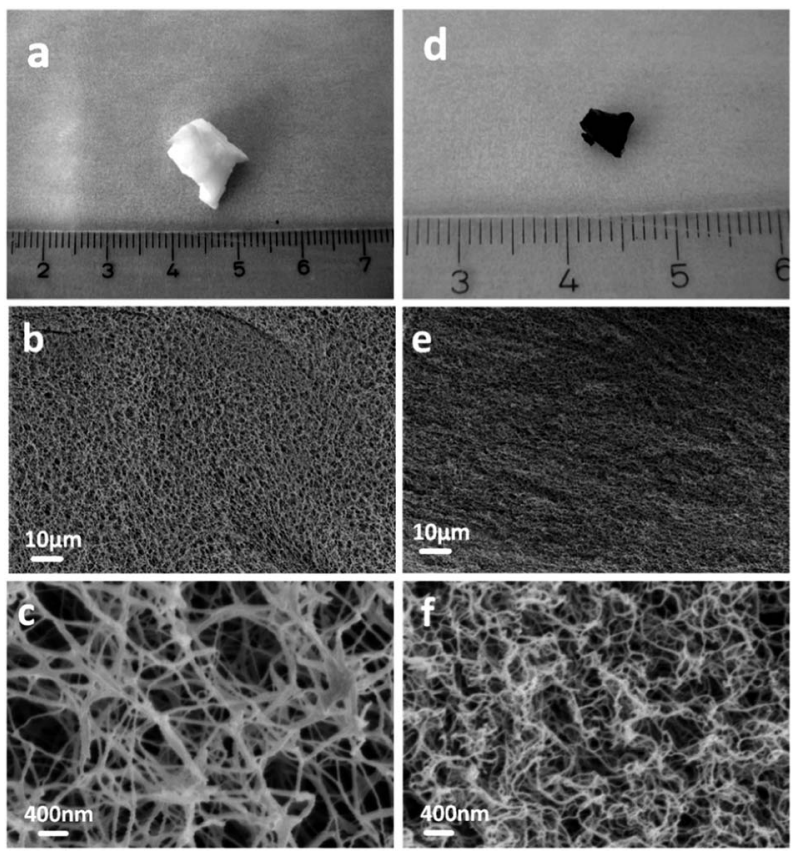

Fig. 1 Morphology of bacterial nanocellulose and carbon aerogels. (a) Photograph of a freeze-dried bacterial nanocellulose aerogel (FD$\mathrm{BNC}$ ), (b and c) SEM images of FD-BNC aerogels at different magnifications, (d) photograph of a carbon aerogel obtained through pyrolysis of freeze-dried bacterial nanocellulose at $900{ }^{\circ} \mathrm{C}$ (FD-BNC900), (e and f) SEM micrograph of FD-BNC-900 aerogels at different magnifications.

gel body can lead a large shrinkage and collapse the network structure by capillary forces acting on the pore walls. ${ }^{32}$ However, although different drying techniques have been explored to maintained the porosity of nanocellulose-based materials, ${ }^{33}$ the freeze-drying method can circumvent the drawbacks of direct thermal treatment and preserve the open porous networks. ${ }^{19}$

The obtained BNC-derived carbon (FD-BNC-900) was subsequently used as the anode in LIBs. The charge-discharge curves at a current density of $75 \mathrm{~mA} \mathrm{~g}^{-1}$, namely $0.2 \mathrm{C}(1 \mathrm{C}=372 \mathrm{~mA}$ $\mathrm{g}^{-1}$ ), are shown in Fig. 2a. The initial discharge and charge capacity are $797 \mathrm{~mA} \mathrm{~h} \mathrm{~g}^{-1}$ and $386 \mathrm{~mA} \mathrm{~h} \mathrm{~g}^{-1}$, respectively. The cycling performance and coulombic efficiency of the BNCderived material were also studied as shown in Fig. 2b. The initial charge capacity of $386 \mathrm{~mA} \mathrm{~h} \mathrm{~g}^{-1}$ decreased to $359 \mathrm{~mA} \mathrm{~h} \mathrm{~g}^{-1}$ after 100 cycles. After an initial adjustment of the coulombic efficiency, probably due to stabilisation of the solid electrolyte interphase and the disordered structure. ${ }^{\mathbf{8 3 4}}$ The capacity increases slightly during the cycling, likely due to the activation of the disordered structure. ${ }^{34}$ The capacity fade rate can be calculated to be $0.07 \%$ per cycle, which means that the capacity retention ability is very good. The capacity of the carbon aerogel as electrode is considerably better than that obtained for carbonized films produced also from BNC, which was reported to be just about $100 \mathrm{~mA} \mathrm{~h}{ }^{-1} \cdot{ }^{35}$ The cellulose-derived carbon shows also a superior rate performance (Fig. 2c). The cell was directly discharged-charged at various current densities from $0.375 \mathrm{~A}$ $\mathrm{g}^{-1}(1 \mathrm{C})$ to $3.75 \mathrm{~A} \mathrm{~g}^{-1}(10 \mathrm{C})$ each for 10 cycles. The reversible capacities are $288,228,94$, and $34 \mathrm{~mA} \mathrm{~h} \mathrm{~g}^{-1}$ at $0.375 \mathrm{~A} \mathrm{~g}^{-1}(1 \mathrm{C})$,
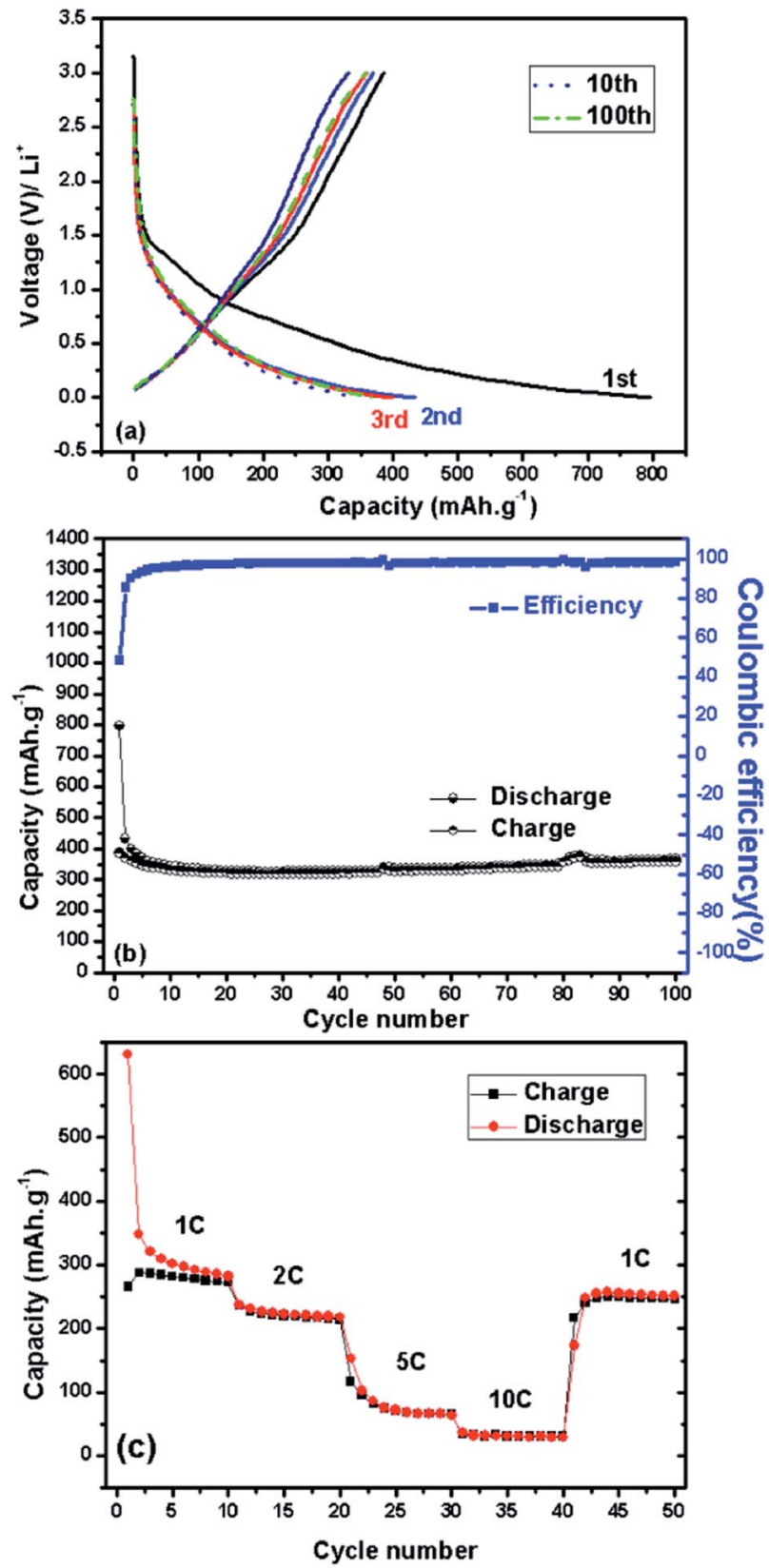

Fig. 2 Electrochemical performance of FD-BNC-900. (a) Chargedischarge curves at a current rate of $75 \mathrm{~mA} \mathrm{~g}^{-1}(0.2 \mathrm{C})$. (b) Capacity retention and coulombic efficiency as a function of cycle number and its (c) rate performance.

$0.75 \mathrm{Ag}^{-1}$ (2 C), $1.875 \mathrm{Ag}^{-1}$ (5 C), and $3.75 \mathrm{Ag}^{-1}$ (10 C, namely 6 minutes to full charge), respectively. When the rate is tuned back to $0.375 \mathrm{Ag}^{-1}$ after cycling at different current rates, the capacity can be recovered to $250 \mathrm{~mA} \mathrm{~h} \mathrm{~g}{ }^{-1}$, which evidences the stable cycling performance of the freeze-dried carbon aerogel.

Compared with mesoporous carbons ${ }^{7,8}$ our sample exhibits a lower capacity but a much better capacity retention behavior at the same current rate of $0.2 \mathrm{C}$. The superior electrochemical performance of the carbon aerogel is attributed to its high surface area, open 3D network and the crosslinking between the carbon nanofibres. The high surface area and open pore 
structure offer a large electrode/electrolyte contact area, favorable for charge-transfer reaction, whereas the crosslinking of the nanofibres ensures a continuous electron transport. Moreover, the thin fibres with diameters of about $20 \mathrm{~nm}$ guarantee a very short diffusion distance for the lithium ion. All of these parameters are indispensable for the stable capacity and high rate performance.

In order to investigate the porosity of the FD-BNC and FDBNC-900, $\mathrm{N}_{2}$ sorption isotherms have been recorded (Fig. 3). The FD-BNC has a total pore volume of $0.23 \mathrm{~cm}^{3} \mathrm{~g}^{-1}$ and a BET surface area of $109 \mathrm{~m}^{2} \mathrm{~g}^{-1}$, characteristic of materials without any apparent pores. After pyrolysis at $900{ }^{\circ} \mathrm{C}$ in $\mathrm{N}_{2}$, the shape of the adsorption isotherm is maintained suggesting the maintenance of the structure and the presence of micropores. The BET surface area and the pore volume of FD-BNC-900 increased to $670 \mathrm{~m}^{2} \mathrm{~g}^{-1}$ and $0.83 \mathrm{~cm}^{3} \mathrm{~g}^{-1}$, respectively. The enhancement of surface area and pore volume can be ascribed to removal of water from the cellulose structure and the severe contraction of the fibres from about $50 \mathrm{~nm}$ to about $20 \mathrm{~nm}$ during pyrolysis. Compared with traditional carbon nanofibres with high surface area normally obtained by chemical or physical activation with tedious work, our procedure is much easier and greener.

Fig. 4a and $\mathrm{b}$ show the XRD profiles of FD-BNC and its carbon residue after pyrolysis. The XRD pattern of FD-BNC
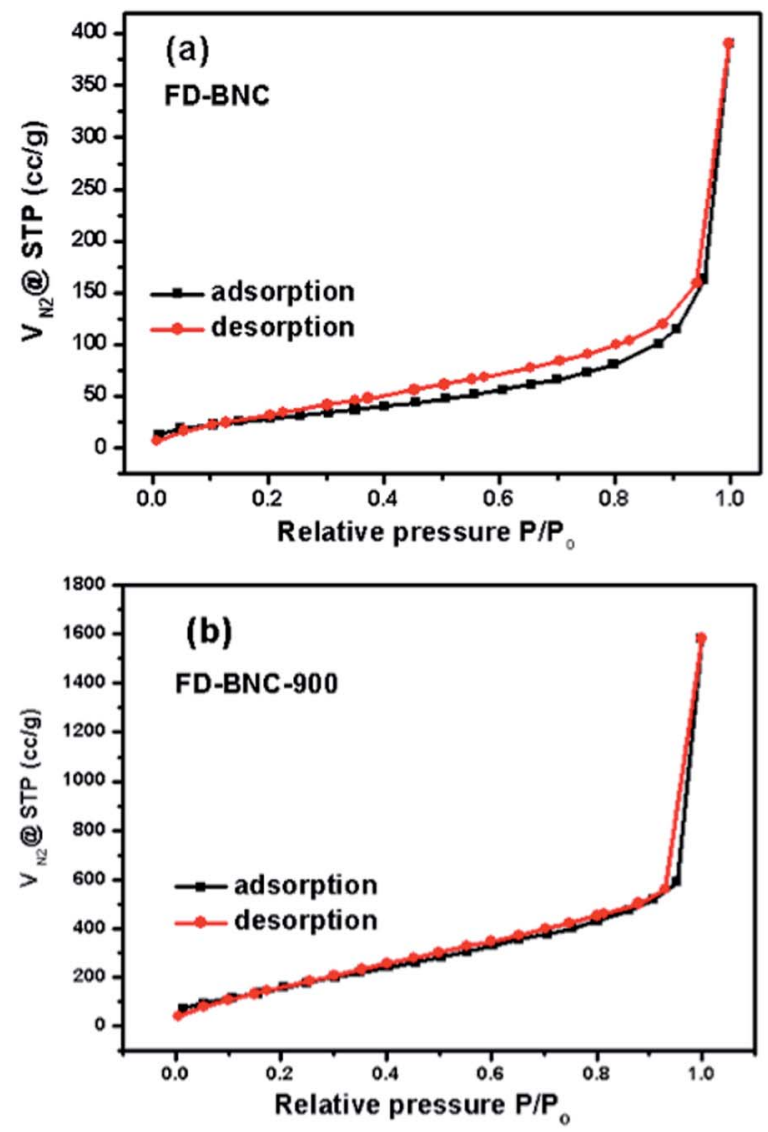

Fig. 3 Nitrogen sorption isotherms of (a) freeze-dried bacterial nanocellulose (FD-BNC) aerogels and (b) freeze-dried bacterial nanocellulose pyrolyzed at $900{ }^{\circ} \mathrm{C}$ (FD-BNC-900). aerogels were identified as cellulose $I_{\alpha}$ (ref. 16) and the characteristic peaks observed at $14.2^{\circ}, 16.7^{\circ}$, and $22.6^{\circ}$ were indexed as the (010), (001), and (011) reflections of the triclinic unit cell, respectively. ${ }^{36}$ The characteristic sharp peaks indicate that the bacterial cellulose is highly crystalline, in agreement with other reports. ${ }^{30,37}$ The pyrolysis of BNC resulted in a graphitic-like structure with broad reflection peaks at ca. $24^{\circ}$ and $43^{\circ}$, which can be assigned to the (002) and (100) lattice planes of graphite,
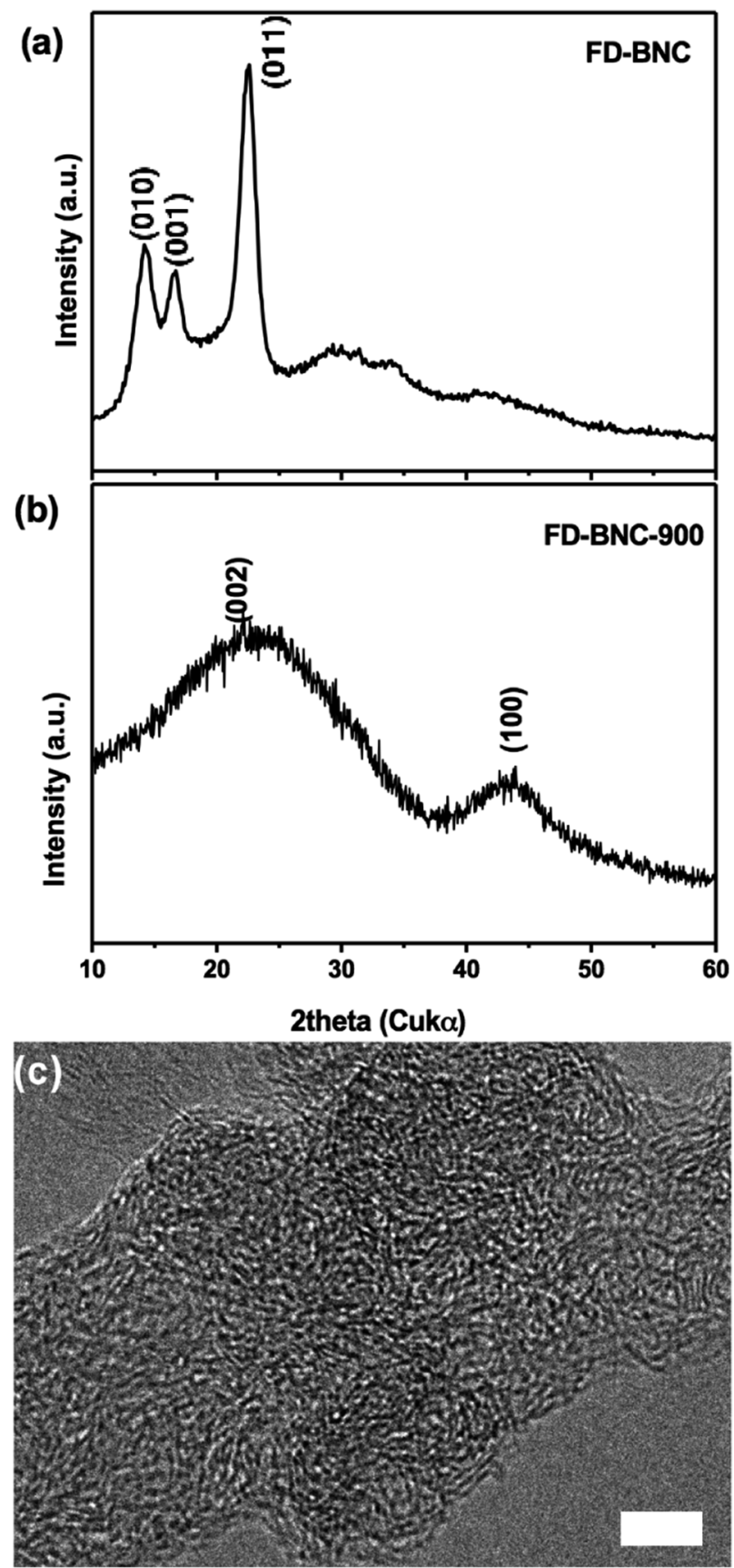

Fig. 4 XRD patterns of (a) freeze-dried bacterial nanocellulose (FD$\mathrm{BNC}$ ) aerogels and (b) freeze-dried bacterial nanocellulose pyrolyzed at $900{ }^{\circ} \mathrm{C}$ (FD-BNC-900). (c) High resolution transmission electron microscopy image of a fiber in FD-BNC-900. The scale bar corresponds to $5 \mathrm{~nm}$. 
respectively; in agreement with earlier reports. ${ }^{38}$ Interestingly, the relatively low pyrolysis temperature resulted in a disordered (and perhaps turbostratic) graphitic structure, as displayed in Fig. 4c. However, it has also been suggested that such relatively disordered structures may result in a decreased capacity, ${ }^{\mathbf{4}, 39}$ these misaligned regions may be the origin of the increased surface area and higher rate performance. ${ }^{4}$

The overall yield, considering the carbon content of nanocellulose after carbonization, is about 25\%, which was improved when the BNC was soaked with iron(III) ion as dehydrating agent (FD-BNC-Fe1200). The elemental analysis of the samples is provided in Table 1 . The analysis indicates that sample FD-BNC-900 has a final carbon content is $90.96 \mathrm{wt} \%$ and a small amount of other elements, where most likely oxygen is still present in the fibres probably as aldehyde groups, carbonates or carboxylates, in agreement with recent results. ${ }^{30}$ The sample soaked with iron shows a much lower hydrogen content, reflecting a more efficient pyrolysis.

Fig. 5a shows the carbon fibres decorated with 10-30 nm iron-based nanoparticles with a composition close to that of cementite $\left(\mathrm{Fe}_{3} \mathrm{C}\right)$. The fibres retained the nanoscale dimensions and the BET surface area increased from $33 \mathrm{~m}^{2} \mathrm{~g}^{-1}$ to $351 \mathrm{~m}^{2}$ $\mathrm{g}^{-1}$ after the pyrolysis process (Fig. 5b), which is expected for the pyrolysed fibres decorated with $\mathrm{ca} .40 \mathrm{wt} \%$ nanoparticles. In comparison to the FD-BNC-900, the FD-BNC-Fe1200 has a slower performance but it has a remarkable stability. The rate performance of the iron doped carbon aerogel is stable and shows a recovery to $220 \mathrm{~mA} \mathrm{~h} \mathrm{~g}^{-1}$ after 45 cycles at different current rates. Fig. 6 shows the Raman spectra for both FD-BNC900 and FD-BNC-Fe1200. Albeit broad, both spectra display the $\mathrm{D}$ and $\mathrm{G}$ bands, characteristic for 6-membered aromatic rings, ${ }^{40}$ at ca. 1340 and $1580 \mathrm{~cm}^{-1}$, respectively. The presence of the bands and their relative ratio, $I_{\mathrm{D}} / I_{\mathrm{G}}$, indicates a graphitic correlation length of $c a .1 \mathrm{~nm},{ }^{40}$ in agreement with the HRTEM images. In the case of FD-BNC-Fe1200, the bands are sharper and also the 2D overtone band (at $c a .2680 \mathrm{~cm}^{-1}$ ) is clearly visible, indicating a somewhat higher degree of structural order.

A drawback observed in the electrochemical performance of the tested materials is the large irreversible capacity. This can be due to three different processes: the decomposition of electrolyte, formation of solid electrolyte interphase (SEI), as well as reaction of lithium with the hydrogen present in the sample (see Table 1). The common carbonate-based electrolyte solution (e.g. EC-DEC, EC-DMC) can easily have a reduction reaction below $1.0 \mathrm{~V}$ (versus $\mathrm{Li}^{+}$) and an oxidation reaction above the voltage of $4.5 \mathrm{~V}$ (versus $\mathrm{Li}^{+}$) to form an electronically insulating but lithium ion conductive film on the electrode active material. ${ }^{2}$ The H/C molar ratio of the pyrolyzed aerogel is relatively low,

Table 1 Elemental analysis of nanocellulose (FD-BNC) and carbon (FD-BNC-900 and FD-BNC-Fe1200) aerogels

\begin{tabular}{lllll}
\hline Sample & $\mathrm{C} / \mathrm{wt} \%$ & $\mathrm{H} / \mathrm{wt} \%$ & Others/wt $\%$ & $\mathrm{H} / \mathrm{C}$ mol ratio \\
\hline FD-BNC & 43.07 & 5.83 & 51.10 & 1.624 \\
FD-BNC-900 & 90.96 & 1.63 & 7.41 & 0.215 \\
FD-BNC-Fe1200 & 60.47 & 0.23 & 39.30 & 0.046
\end{tabular}
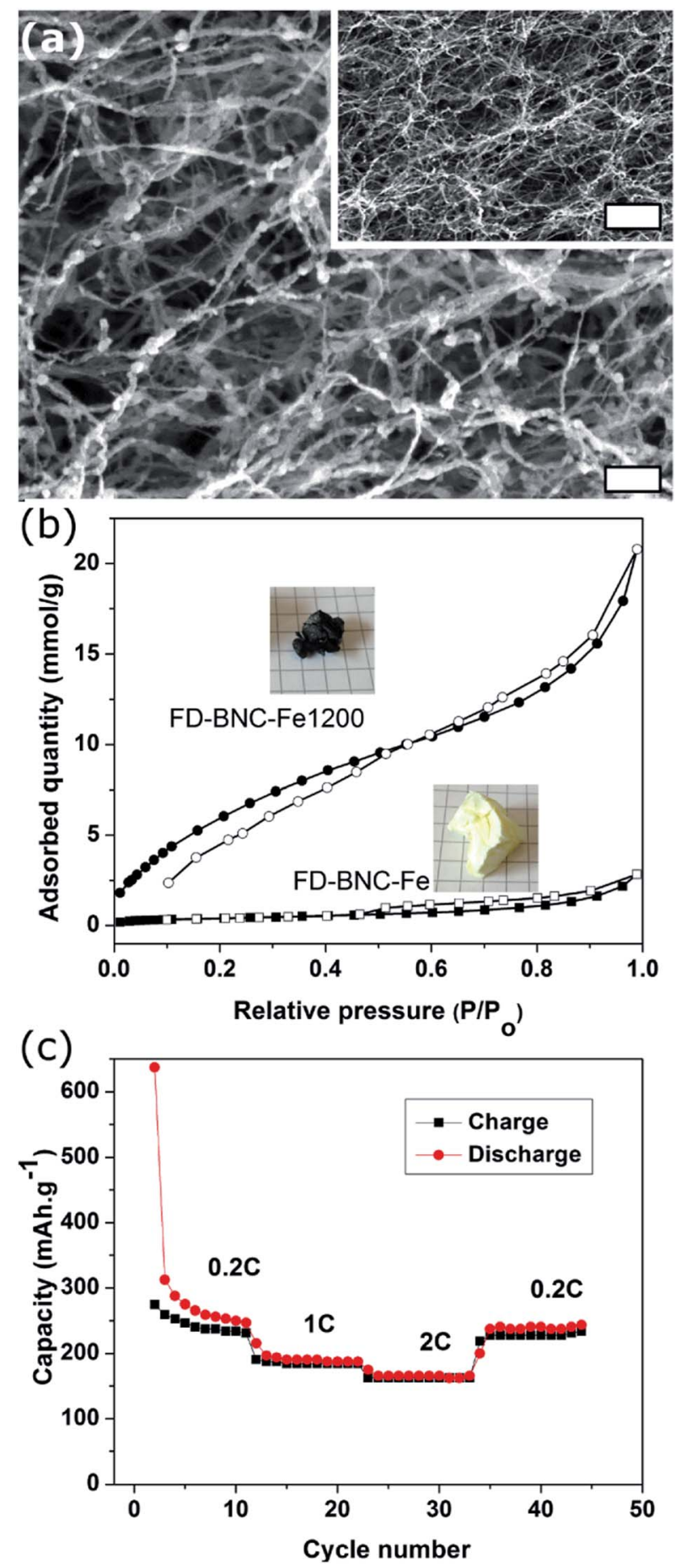

Fig. 5 (a) SEM images of FD-BNC-Fe1200 aerogels at different magnifications. Scale bars: $200 \mathrm{~nm}$, inset: $1 \mu \mathrm{m}$. (b) Adsorption (full symbols) and desorption (open symbols) isotherms for the Fe(III) soaked aerogel (FD-BNC-Fe, squares) and the pyrolysed Fe(III) aerogel (FD-BNC-Fe1200, circles). The insets show conventional photographs of the aerogels before and after pyrolysis. (c) Electrochemical rate performance of FD-BNC-Fe1200.

i.e., $\mathrm{H} / \mathrm{C}=0.215$, but seems to influence the electrochemical performance, being the effect particularly noticeable in the first cycle, where the capacity is well beyond the theoretical limit of graphite. The capacity obtained in this first cycle is indeed 


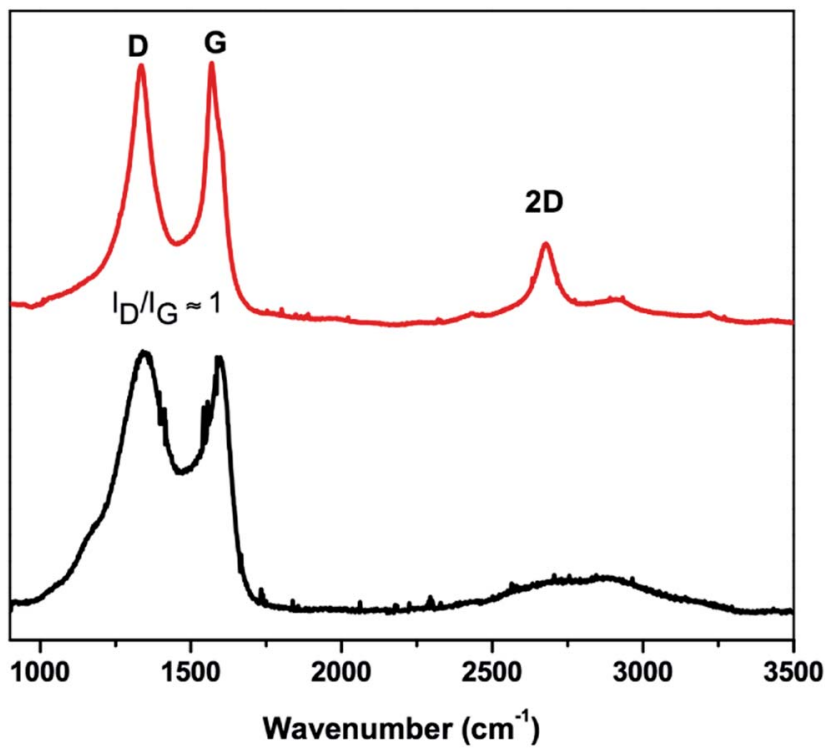

Fig. 6 Raman spectra of (bottom trace) FD-BNC-900 and (top trace) FD-BNC-Fe1200. The different bands are labelled and the $I_{D} / I_{G}$ ratio is indicated.

matching that expected for one lithium atom being bound by one hydrogen atom, i.e., ca. $800 \mathrm{~mA} \mathrm{~h} \mathrm{~g}{ }^{-1} .^{4}$ However, the capacity and the shape of charge-discharge curves are quite similar after the first cycle, suggesting that the formation of the SEI stabilizes after the initial cycle. Herein, we have to emphasize that if we expect to build a lithium ion cell, understanding and controlling the phenomena occurring during the initial cycles is always primordial independent of the electrode material with low operation voltage as anode or with high operation voltage as cathode.

\section{Conclusions}

In this study, the fabrication of a carbon aerogel composed of nanofibres of about $20 \mathrm{~nm}$ in diameter was accomplished by pyrolysis of the readily available bacterial nanocellulose (BNC). The 3D open network of the BNC aerogel was preserved from capillary-induced shrinkage and collapse through a freeze-drying method before calcination. The carbon nanofibres showed high surface area and pore volume which favors mass transportation and leads to a very good electrochemical performance in terms of both capacity retention as well as rate performance. The present work can possibly broaden the possibility of an economical and ecofriendly use of cellulose to produce 3D open networks of carbon nanofibres not only for energy storage applications but also for other applications such as adsorption, (electro)catalysis, chromatography or even medical applications. We can already foresee that such an interesting and disordered carbon morphology will have a good performance in Na-ion batteries systems which is a new emerging technology giving the limited availability of lithium and the abundance and low cost of sodium around the globe.

\section{Experimental}

\subsection{Pyrolysis of BNC}

Coconut gel cubes (ca. $1 \times 1 \times 1 \mathrm{~cm}^{3}$, Chaokoh, Thailand) were washed three times with $2 \mathrm{dm}^{3}$ of deionized water and stirred in $2 \mathrm{dm}^{3}$ of a $0.1 \mathrm{M}$ sodium hydroxide solution for 48 hours to remove any adsorbed components. The materials were further washed with deionized water until the $\mathrm{pH}$ stabilized at around 7. The BNC cubes were frozen in liquid nitrogen $\left(-196{ }^{\circ} \mathrm{C}\right)$ and freeze-dried in a vacuum chamber at a temperature of $-80^{\circ} \mathrm{C}$. The freeze-dried BNC aerogels (labeled as FD-BNC) were then pyrolyzed under $\mathrm{N}_{2}$ at $900{ }^{\circ} \mathrm{C}$ for 2 hours using a heating rate of $30{ }^{\circ} \mathrm{C} \min ^{-1}$ to obtain monolithic black carbon (denoted as FDBNC-900). Alternatively, the freeze-dried BNC cubes (FD-BNC) were soaked with a $0.005 \mathrm{M} \mathrm{FeCl}_{3}$ solution and subsequently freeze-dried (FD-BNC-Fe). The pyrolysis was carried out under argon atmosphere at $1200{ }^{\circ} \mathrm{C}$ for 2 hours and a heating rate of 1 ${ }^{\circ} \mathrm{C} \min ^{-1}$ (denoted as FD-BNC-Fe1200).

\subsection{Characterisation}

The size and morphology of all the samples were visualized using electron microscopy facilities (Gemini Leo-1550 SEM or Jeol JEM-7401 SEM and Omega 912 TEM). Nitrogen adsorption/ desorption isotherms were measured at $77 \mathrm{~K}$ using a Quantachrome Quadrasorb Adsorption Instrument or a Micromeritics ASAP 2020 where the BET method was used for surface area determination. Elemental composition was determined using a Vario E1 elemental analyzer. XRD patterns were recorded with a Bruker-D8 apparatus with $\mathrm{Cu}$ radiation. Each pattern was recorded with a step size of $0.03^{\circ}$. TGA was performed on a Perkin-Elmer Thermogravimetric Analyzer TGA7. The Raman spectra were recorded with a Horiba LabRAM HR 800 spectroscope using a $532 \mathrm{~nm}$ laser.

\subsection{Electrochemical test}

The electrode was prepared by mixing powder (80 wt \%), carbon black (10 wt\%), and polyvinylidene fluoride (PVDF, $10 \mathrm{wt} \%$ ) in $N$-methylpyrrolidone (NMP) to form a homogenous slurry. The slurry was then spread onto a copper foil and dried at $100{ }^{\circ} \mathrm{C}$ for overnight in a vacuum oven. $1 \mathrm{M} \mathrm{LiPF}_{6}$ in a mixture of ethylene carbonate (EC), dimethyl carbonate (DMC) ( $1: 1$ by volume) was used as the electrolyte. The assembly of the test cells was carried out in an argon-filled glove box. The batteries were charged and discharged at different rates from $0.2 \mathrm{C}$ to $10 \mathrm{C}$ between 0.0 and $3.0 \mathrm{~V}$ on a LAND CT2001A cell test apparatus (1 C corresponding to $372 \mathrm{~mA} \mathrm{~g}^{-1}$ of current rate).

\section{Acknowledgements}

We would like to thank Rui Wang (Institute of Physics, Chinese Academy of Sciences) for help of electrochemical measurements and Markus Antonietti (Max Planck Institute of Colloids and Interfaces) for providing LW with a post-doctoral fellowship. CS and GSA thank the Wallenberg Wood Science Center for financial support and the Knut and Alice Wallenberg 
Foundation for the electron microscopy facilities, and Eva Björkman (Stockholm University) for fruitful discussions.

\section{References}

1 J. M. Tarascon and M. Armand, Nature, 2001, 414, 359-367.

2 J. B. Goodenough and Y. Kim, Chem. Mater., 2010, 22, 587603.

3 K. Sawai, Y. Iwakoshi and T. Ohzuku, Solid State Ionics, 1994, 69, 273-283.

4 J. R. Dahn, T. Zheng, Y. Liu and J. S. Xue, Science, 1995, 270, 590-593.

5 M. Wakihara, Mater. Sci. Eng., R, 2001, 33, 109-134.

6 M. V. Reddy, G. V. Subba Rao and B. V. R. Chowdari, Chem. Rev., 2013, 113, 5364-5457.

7 H. Zhou, S. Zhu, M. Hibino, I. Honma and M. Ichihara, Adv. Mater., 2003, 15, 2107-2111.

8 Y.-S. Hu, P. Adelhelm, B. M. Smarsly, S. Hore, M. Antonietti and J. Maier, Adv. Funct. Mater., 2007, 17, 1873-1878.

9 B. Guo, X. Wang, P. F. Fulvio, M. Chi, S. M. Mahurin, X.-G. Sun and S. Dai, Adv. Mater., 2011, 23, 4661-4666.

10 B. Wicklein and G. Salazar-Alvarez, J. Mater. Chem. A, 2013, 1, 5469.

11 F. Zhang, K.-X. Wang, G.-D. Li and J.-S. Chen, Electrochem. Commun., 2009, 11, 130-133.

12 A. Caballero, L. Hernán and J. Morales, ChemSusChem, 2011, 4, 658-663.

13 B. Hu, K. Wang, L. Wu, S.-H. Yu, M. Antonietti and M.-M. Titirici, Adv. Mater., 2010, 22, 813-828.

14 Q. Wang, H. Li, L. Chen and X. Huang, Carbon, 2001, 39, 2211-2214.

15 D. Klemm, F. Kramer, S. Moritz, T. Lindström, M. Ankerfors, D. Gray and A. Dorris, Angew. Chem., Int. Ed., 2011, 50, 54385466.

16 R. J. Moon, A. Martini, J. Nairn, J. Simonsen and J. Youngblood, Chem. Soc. Rev., 2011, 40, 3941-3994.

17 C. Aulin, J. Netrval, L. Wågberg and T. Lindström, Soft Matter, 2010, 6, 3298.

18 A. Isogai, T. Saito and H. Fukuzumi, Nanoscale, 2011, 3, 7185.

19 H. Sehaqui, M. Salajkova, Q. Zhou and L. A. Berglund, Soft Matter, 2010, 6, 1824-1832.
20 H. Jin, M. Kettunen, A. Laiho, H. Pynnönen, J. Paltakari, A. Marmur, O. Ikkala and R. H. A. Ras, Langmuir, 2011, 27, 1930-1934.

21 N. Cervin, C. Aulin, P. Larsson and L. Wågberg, Cellulose, 2012, 1-10.

22 M. Iguchi, S. Yamanaka and A. Budhiono, J. Mater. Sci., 2000, 5, 261-270.

23 R. T. Olsson, M. A. S. Azizi Samir, G. Salazar-Alvarez, L. Belova, V. Ström, L. A. Berglund, O. Ikkala, J. Nogués and U. W. Gedde, Nat. Nanotechnol., 2010, 5, 584-588.

24 A. N. Nakagaito, M. Nogi and H. Yano, MRS Bull., 2011, 35, 214-218.

25 G. Nyström, A. Razaq, M. Strømme, L. Nyholm and A. Mihranyan, Nano Lett., 2009, 9, 3635-3639.

26 L. Hu, N. Liu, M. Eskilsson, G. Zheng, J. McDonough, L. Wågberg and Y. Cui, Nano Energy, 2013, 2, 138-145.

27 S. Leijonmarck, A. Cornell, G. Lindbergh and L. Wågberg, J. Mater. Chem. A, 2013, 1, 4671.

28 H.-W. Liang, Q.-F. Guan, Z. Zhu, L.-T. Song, H.-B. Yao, X. Lei and S.-H. Yu, NPG Asia Mater., 2012, 4, e19.

29 B. Wang, X. Li, B. Luo, J. Yang, X. Wang, Q. Song, S. Chen and L. Zhi, Small, 2013, 9, 2399-2404.

30 Z.-Y. Wu, C. Li, H.-W. Liang, J.-F. Chen and S.-H. Yu, Angew. Chem., Int. Ed., 2013, 52, 2925-2929.

31 M. Tang and R. Bacon, Carbon, 1964, 2, 211-220.

32 N. Hüsing and U. Schubert, Angew. Chem., Int. Ed., 1998, 37, 22-45.

33 A. Svensson, T. Larsson, G. Salazar-Alvarez and L. Wågberg, Carbohydr. Polym., 2012, 92, 775-783.

34 L. Wang, Z. Schnepp and M. M. Titirici, J. Mater. Chem. A, 2013, 1, 5269.

35 H. Take, S. Yamanaka, M. Ishihara and K. Yoshino, Jpn. J. Appl. Phys., 2002, 41, 3137-3139.

36 Y. Nishiyama, J. Sugiyama, H. Chanzy and P. Langan, J. Am. Chem. Soc., 2003, 125, 14300-14306.

37 D. Klemm, B. Heublein, H.-P. Fink and A. Bohn, Angew. Chem., Int. Ed., 2005, 44, 3358-3393.

38 S. Kuga, D.-Y. Kim, Y. Nishiyama and R. M. Brown, Mol. Cryst. Liq. Cryst., 2002, 387, 13-19.

39 J. L. Tirado, Mater. Sci. Eng., R, 2003, 40, 103-136.

40 A. Ferrari and J. Robertson, Phys. Rev. B, 2000, 61, 1409514107. 